\title{
Curriculum Management Study: Origin, Development, Current Situation and Trend
}

\author{
Rendong Jin \\ Doctoral student of College of Education, Zhejiang University \\ Associate professor of Zhejiang Tongji Vocational College of Science and Technology \\ Hangzhou, China
}

\begin{abstract}
Learners, educators and curricula are critical to educational activities. Studying curriculum management has to be within content. It requires the focus on its origin, development, current situation and trend. Therefore, with the data from Web of Science, an analysis is carried out in the present paper. Curriculum management study originated from curricula criteria development, and has been mainly focusing on how to improve educational effectiveness and qualification practically to meet the needs of the industry. A high percentage of the published research has been done by American university researchers. Curriculum management study is inter-disciplinary, systematical, and is attracting more and more attention globally.
\end{abstract}

Keywords-higher education; curriculum management; educational management; curriculum and instruction

\section{INTRODUCTION}

Curriculum management manages all educational activities related to curriculum. It is critical to educational activities, because educational aims are realized via instruction. Although there has not been a clear definition about what curriculum management is, which could be issued by authorities or agreed to by the research circle, in varied aspects within a diversity of processes, fruitful curriculum management studies have answered what to teach and how to teach. Focusing on the origin, development, current situation and trend of curriculum management study, the present paper has utilized all the databases indexed by Web of Science with the key word "curriculum management" as either topic or title from 1954 to 2019 (Feb. 16th) to further understand what is it and what are its future research leaders and focus, as well as development forces, barriers and suggestions.

\section{ORIGIN AND DEVELOPMENT}

Curriculum management study originated from 1954. "Developing criteria for institution management curricula" [1] was published in Journal of the American Dietetic Association which began the discussion of how to regulate instruction for future dieticians.

Grounding on the shared concern of what to teach and how to teach to meet the needs of the industry, until Feb. 16th 2019, there have been 20009 records into this focus which is with "curriculum management" as a research topic, and the attention has been soaring since 2000. From 2000 to 2019 (Feb.

Sponsors: 1. Construction and Practice of Vocational College English Curriculum System----From the Curriculum Nature Perspective (2018ZJ0028A), National Vocational College Foreign Language Teaching Reform Research; 2. CLIL Based Vocational College English Curriculum and Instruction (TRC1806), Zhejiang Tongji Vocational College of Science and Technology Research Program. 16th), there are 17481 records, which accounts for $87.4 \%$ of all the digital records found. In 2017, the amount of the annually published records reached the peak.

Meanwhile, with “curriculum management” in paper titles, there have been 927 records during the entire time span and from 2000 to 2019 (Feb. 16th), there are 794 ones. The annually published record amount peak was reached in 2016. The amount of cited times of all these records by either the authors or other researchers is 1795 and 1734, which in total is almost four times of its own amount.

\section{CURRENT SITUATION}

\section{A. Research Width Review}

The first part of the current situation analysis is based on records searched for with "curriculum management" as a research topic.

Curriculum management study exists in varies fields. The research domains mainly include social science $(13,984$ 79.995\%), science technology (12,084 69.126\%), life science biomedicine (8,866 50.718\%), technology (4,436 25.376\%), physical science (979 5.600\%) and arts humanities (690 $3.947 \%)$

Top ten research areas mainly include educational research (11,763 67.290\%), health care science services (4,656 $26.635 \%)$, psychology (3,712 21.234\%), behavioral sciences (3,596 20.571\%), computer science (2,726 15.594\%), business economics (2,368 13.546\%), engineering (1,845 10.554\%), general internal medicine (1,746 9.988\%), public environmental occupational health (1,508 8.627\%), and nursing (1,369 $7.831 \%)$. The top research area is education, while studies in other areas are also concerned with curriculum management. The total amount percentage of all records found in different research areas is almost 200\%, which shows records were recalculated in different research areas. This declares curriculum management study is interdisciplinary.

The top ten authors are anonymous (96 records), Wang J (18 records), Watt-Watson J (16 records), Aggarwal R (15 records), Darzia (15 records), Wand H (15 records), Aggarwal Rajesh (14 records), Darzi Ara (14 records), Grant M (14 records), Hong Hoo-jo G (14 records). These authors are leading figures in curriculum management study. Interestingly, top one author is "anonymous" who is actually not a person but an institution, and all these anonymous published records are mainly guidelines, which regulate practical instruction 
processes and standards in industries. The top five of these guidelines are: "Cancer Pain Assessment and Treatment Curriculum Guidelines"; "Hallmarks of quality and patient safety: Recommended baccalaureate competencies and curricular guidelines to ensure high-quality and safe patient care"; "Time for education in palliative care"; "Hallmarks of excellence in nursing education" and "Curriculum guidelines for practice administration”.

Although the records come from countries or regions all over the world, American records have occupied 30.067\% (5,256 records) of all and so the USA ranked the top, while the People's Republic of China and Britain ranked the second and the third with occupation of $6.212 \%$ (1,086 records) and $5.886 \%(1,029$ records), respectively. According to the record amount ranking, the top ten research institutions are all universities: University of California System, Harvard University, Florida State University, Pennsylvania Commonwealth System of Higher Education, University of Texas System, University of North Carolina, University of Toronto, University of Washington, University of Washington Seattle, and University of London.

Record sources are journals or conference collections which focus either on how to educate the future specialties for varies careers or on education in general. The top ten are: science education journal "INTED PROCEEDINGS", medicine education journal "ACADEMIC MEDICINE JOURNAL OF THE ASSOCIATION OF AMERICAN MEDICAL COLLEGES" and "ACADEMIC MEDICINE", learning technology education oriented conference collection "EDULEARN PROCEEDINGS", social science education and humanity research journal "ADVANCES IN SOCIAL SCIENCE EDUCATION AND HUMANITIES RESEARCH”, medicine education journal "MEDICAL TEACHER", engineering education oriented conference collection "ASEE ANNUAL CONFERENCE EXPOSITION", medicine education journal "JOURNAL OF DENTAL EDUCATION", and "BMC MEDICAL EDUCATION", as well as education oriented conference collection "ICERI PROCEEDINGS".

\section{B. Research Depth Review}

The second part of current situation analysis is based on the records searched for with "curriculum management" in paper titles.

The research domains mainly include science technology (54,314 80.561\%), social science (51,259 76.029\%), life science biomedicine (34,543 51.236\%), technology (25,673 $38.079 \%)$, physical science (6,954 10.314\%) and arts humanities (2,156 3.198\%). The ranking result is similar to the one searched out with "curriculum management" as a research topic.

The top ten research areas mainly include educational research (565 60.949\%), health care science services (159 17.152\%), computer science (147 15.858\%), engineering (126 13.592\%), business economics (104 11.219\%), psychology (93 10.032), general internal medicine (86 9.277\%), behavioral sciences (85 9.169\%), social science other topics (68 7.35\%), and nursing (53 5.717\%). The ranking result is similar to the one searched out with "curriculum management" as a research topic too. Therefore, curriculum management study is targeting how to realize educational aims practically throughout all industries by researchers not only from educational circle.

The top research area is still education, and among all 565 records found, including 16 papers whose citation times are 20 or more than 20. These papers focused on the aim, content, application and evaluation of curricula as well as the development of curricula for special purposes.

The top ten authors are anonymous (6 records), Ulriche (5 records), Choi Sung Kyu (4 records), Fang R J (3 records), Habermann Monika (3 records), Hanleyk (3 records), Hussein I H (3 records), Hur Changsoo (3 records), Huang $\mathrm{Y}$ (3 records), Hussein Inaya Hajj (3 records). This ranking list is different from the previous one. Since the amount of the papers whose authors are on the list is very small, curriculum management study by beginning and leading researchers are still beginners compared with those leading researches in other fields. The content of these researches focus on curriculum design and application in general, trying to discuss with different educational aims and backgrounds on how education is realized by curriculum and instruction.

Only American universities are on the list of top ten institution publication amount list, University of Toronto and University of London are no longer on. The top ten institutions are: University of California System, Harvard University, University of Texas System, New York University, Pennsylvania Commonwealth System of Higher Education, State University of New York SUNY System, University of North Carolina, California State University System, University of California San Francisco, and University of Illinois System. Surprisingly, the top one institution only published 16 papers. According to existed digital data, curriculum management study was original in 1954, and has been developing for 65 years. As educational research frontiers and authorities, why American universities have paid little attentions to curriculum management study which is critical and practical in education research and application?

The record source top ten lists is similar to the previous one, on which there are medicine journals, science education and humanity research journals, engineering education oriented conference collections, medicine education journals, education oriented conference collections, education research journals, and learning technology education oriented conference collections. They are: "JOURNAL OF GENERAL INTERNAL MEDICINE”, “ADVANCES IN SOCIAL SCIENCE EDUCATION AND HUMANITIES RESEARCH", "ASEE ANNUAL CONFERENCE EXPOSITION", "ACADEMIC MEDICINE JOURNAL OF THE ASSOCIATION OF AMERICAN MEDICAL COLLEGES", "ICERI PROCEEDINGS”, “ACADEMIC MEDICINE”, "JOURNAL OF DENTAL EDUCATION", "NURSE EDUCATION TODAY", "ADVANCES IN EDUCATION RESEARCH", and "EDULEARN PROCEEDINGS". The importance and globalization of educational qualification control via curriculum management have been confirmed again, and have drawn attentions from more and more research circles. 


\section{TREND}

\section{A. Future Research Leaders}

According to the research area and record source top ten lists organized in part III, medicine education curriculum and instruction study has led curriculum management research.

Directly or indirectly, in all the width and depth reviews, top ten research areas related to are health care science services, psychology, behavioral sciences, general internal medicine, public environmental occupational health and nursing. This is 11 out of 20 research areas listed.

More impressively, the top ten record sources related are "ACADEMIC MEDICINE JOURNAL OF THE ASSOCIATION OF AMERICAN MEDICAL COLLEGES”, "ACADEMIC MEDICINE", "MEDICAL TEACHER", "JOURNAL OF DENTAL EDUCATION", "BMC MEDICAL EDUCATION", "JOURNAL OF GENERAL INTERNAL MEDICIN", and "NURSE EDUCATION TODAY”. This is 11 out of 20 publications listed and all of them are on medicine education curriculum and instruction research.

Records with the most amount of citation times with "curriculum management" as a research topic are: the first, "Effective Physician-patient Communication and Health Outcomes" (cited 1966 times) [2]; the second, "Features and uses of high-fidelity medical simulations that lead to effective learning: a BEME systematic review" (cited 1431times) [3]; the third, "1998 guidelines for treatment of sexually transmitted diseases" (cited 861 times) [4]; the fourth, "Beyond curriculum reform: Confronting medicine's hidden curriculum" (cited 797 times) [5]; the ninth, "Wound bed preparation: a systematic approach to wound management"( cited 519 times) [6]. All these papers focused on how to educate future medicine staff so that curricula and instructions can be regulated and effective national wide. With qualified education, medicine operations in real by these future stuff will be professional even during the internship periods, thus hospitals, clinics, public health care institutions or nursing departments are able to improve services.

Meanwhile, there are in total 565 papers in the research area of education with "curriculum management" in paper titles, and there are 16 records cited 20 or more times, among which, only two are not related to medicine. Papers cited for and more than 29 times are: ranked the first, Crisis Resource Management in the undergraduate curriculum” (cited 99 times) [7]; ranked the second, "Curriculum Recommendation for Graduate Professional Programs in Information-System” (cited for 44 times) [8];ranked the third, "Attitudes of medical students to medical leadership and management: a systematic review to inform curriculum development” (cited 38 times) [9]; ranked the fifth, "Can a pain management and palliative care curriculum improve the opioid prescribing practices of medical residents?" (cited 33 times) [10]; ranked the sixth, Leadership and management training for residents and fellows - A curriculum for future medical directors (cited 31 times) [11]; ranked the seventh, "Medical students retain pain assessment and management skills long after an experiential curriculum: A controlled study" (cited 29 times) [12].
Therefore, future research leaders in curriculum management study will be medicine education curriculum and instruction study with both the research forces and possibilities. The needs of medicine education are in urgent, practical and could be as well as should be standardized.

\section{B. Future Research focus}

Future research focus will still be on what to teach and how to teach. Curriculum management is a real life research, as one of the three cores of educational activities; it bridges the educational theories and all curriculum related problems confronted continuously. In details, there are focuses including setting curriculum aims, selecting curriculum contents, realizing curriculum application and curriculum evaluation, as well as development of curricula for special purposes.

\section{SUMMARY}

\section{A. Development Forces}

Curriculum management study began by raising questions as to what to do about curriculum and instruction, and questions that have struck responsive chords in the hearts of not only people in educational circle but also those out of the circle. Everyone is related to education and education is realized by curricula and instruction. People like to join discussions about activities they have ever experienced. The media even guide the changing of topics which ordinary people daily talk about educationally related conversations. Therefore, the desire to realize teaching aims and confusion of how to do drive the development progress. The publication and spreading of fruitful research results benefit people who have the shared confusions, and thus the curriculum management study develops.

\section{B. Development Barriers}

Education should be customized. It should first meet the needs of every learner who has different future careers and learning stereotypes so learners are to be educated properly and scientifically. And so do educators, who cannot be unified in instruction. This situation makes curricula and instruction extremely complicated. The confusion about what to teach and how to teach is shared, however, within varied educational content, there is no standardized answers. The barriers of the development are concrete problems that cannot be thoroughly solved by abstract problem solving guidance.

\section{Development Suggestions}

As the frontiers and authorities of educational researches, universities, especially American ones need to contribute more than what they have done. Although educational theories ground educational researches, there have to be a bridge to realize education practically. Meanwhile, real life curriculum and instruction practices have to solid the theory bases, without knowing the whole picture, problems confronted cannot be solved systematically and scientifically. Researchers in universities should adjust their research perspectives to pay more attention to the real-life educational situations, and provide training and help to support educators in fields realize curricula and instruction. Collections of workshops and conferences solving curriculum management problems are welcomed. 


\section{REFERENCES}

[1] Augustine, GM; Mckiniey, MM; Galster, M D. "Developing criteria for institution management curricula". Journal of the American Dietetic Association,1954,30(5): 458-63

[2] STEWART, MA. "Effective Physician-patient Communication and Health Outcomes - A Review”. Canadian Medical Association Journal, 1995,153(9): 1423-1433

[3] Issenberg, SB; McGaghie, WC; Petrusa, ER. "Features and uses of high-fidelity medical simulations that lead to effective learning: a BEME systematic review”. Medical Teacher, 2005, 27 (1) : 10-28

[4] Centers for Disease Control and Prevention. "1998 guidelines for treatment of sexually transmitted diseases" .Recommendations and reports : Morbidity and mortality weekly report, 1998, 47 (RR-1) : $1-111$

[5] Hafferty, F W "Beyond. curriculum reform: Confronting medicine's hidden curriculum”. Academic Medicine, 1998, 73 (4) : 403-407

[6] Schultz, GS; Sibbald, RG; Falanga, V 9. "Wound bed preparation: a systematic approach to wound management". Wound Repair and Regenetation, 2003, 11 (2S) : S1-S28

[7] Flanagan, B; Nestel, D; Joseph, M. "Making patient safety the focus: Crisis Resource Management in the undergraduate curriculum”. Medical Education, 2004, 38 (1) : 56-66
[8] Adams, Harold P., Jr.; del Zoppo, Gregory; Alberts, Mark J. "Guidelines for the early management of adults with ischemic stroke A guideline from the American Heart ASHENHURST, RL. Curriculum Recommendation for Graduate Professional Programs in Information-System”. Communications of the ACM, 1972, 15 (5) : $363-+$

[9] Abbas, Mark R.; Quince, Thelma A.; Wood, Diana F. “Attitudes of medical students to medical leadership and management: a systematic review to inform curriculum development”. BMC Medical Education, 2011, 11, 93

[10] Ury, WA; Rahn, M; Tolentino, V. "Can a pain management and palliative care curriculum improve the opioid prescribing practices of medical residents?”. Journal of General Internal Medicine, 2002, 17 (8) 625-631

[11] Hemmer, Patrick R.; Karon, Brad S.; Hernandez, James S. "Leadership and management training for residents and fellows - A curriculum for future medical directors". Archives of Pathology \& Laboratory Medicine, 2007, 131 (4) : 610-614

[12] Stevens, D. L.; King, D.; Laponis, R. "Medical students retain pain assessment and management (PAM) skills long after an experientia curriculum: A controlled study”. Journal of General Internal Medicine, 2007, 22 (1) : 88 